\title{
EDITORIAL
}

\section{LA CONSTRUCCIÓN DEL DERECHO EN EL CONTEXTO DE LA BIOÉTICA}

Las sociedades contemporáneas, cuya heterogeneidad cultural y valórica es innegable, exigen al debate bioético un carácter esencialmente pluralista y no dogmático. Esta circunstancia permite la generación de un orden social en el cual la mayoría de los ciudadanos pueda sentirse representada, lo que constituye un eje central en torno al cual se construyen las democracias actuales. Esta afirmación, sin embargo, no se opone a la existencia de principios morales mínimos -como son, v. gr., los derechos humanos consagrados en diversos instrumentos internacionales-, los cuales deben ser respetados por todos los individuos, independientemente de sus concepciones valóricas.

El acuerdo acerca de estos principios básicos no implica automáticamente la existencia de consenso para cada caso en particular. Muy por el contrario, el estado actual del debate bioético deja claramente de manifiesto que la controversia está muy lejos de aplacarse. Frente a la ausencia de consenso moral se hace particularmente necesaria la existencia de normas jurídicas que eviten los conflictos entre concepciones valóricas diversas. Con todo, debemos hacer especial hincapié en que la separación entre la esfera moral y la esfera jurídica es neta: las normas morales se fundan en la adhesión voluntaria de los individuos -imponen deberes, pero no otorgan facultades- y son esencialmente incoercibles; en cambio, las normas jurídicas imponen obligaciones y, además, otorgan facultades, pudiendo exigirse su cumplimiento mediante el uso de la fuerza.

No obstante esta clara separación entre moral y derecho, no cabe duda alguna de que las normas jurídicas deben adecuarse a los principios morales imperantes en la sociedad y, en caso de conflicto moral, deben tratar de resolverlo. Sin embargo, la intervención del derecho debe ser especialmente cuidadosa en el ámbito bioético, donde los conocimientos y las condiciones de existencia de la humanidad están en continua evolución. Las soluciones jurídicas, frente a la imposibilidad de prever completamente el futuro o determinar absolutamente el interés individual, deben ser particularmente flexibles, dejando a los individuos espacios de libertad mayores a los existentes en otros campos del derecho. Normas jurídicas rígidas mas que dar soluciones pueden, muy por el contrario, agravar el conflicto ético. En consecuencia, el legislador debe dictar normas que puedan satisfacer las concepciones morales de todos los individuos, respetando aquellos principios morales mínimos, propios de toda sociedad democrática.

Es también necesario asumir plenamente los desafíos y evitar las dificultades y contradicciones que se yerguen en la construcción de este derecho que responde a las temáticas planteadas por la bioética. No nos anima el deseo de juridificar todos los aspectos de la vida individual y colectiva, pues una actitud de este tipo, en definitiva, tiende a establecer soluciones coercitivas que, muchas veces, no repreesentan el sentir mayoritario de la sociedad, adentrándose el derecho en ámbitos que deberían estar entregados a la sola consciencia individual. En otros casos, la premura legislativa en una área que se encuentra en constante evolución, tiende a establecer soluciones contradictorias, que no guardan armonía con otros campos del ordenamiento jurídico ni con las prácticas sociales. 
Un ejemplo paradigmático de juridificación excesiva se ha presentado en el último tiempo en Chile y Argentina, a propósito de la píldora del día después, donde los tribunales de justicia de esos países se han pronunciado, de manera restrictiva, respecto de una materia que debería estar reservada al ámbito exclusivamente privado. Asimismo, en el ordenamiento jurídico chileno pueden observarse contradicciones flagrantes en relación con las normas sobre transplantes de órganos, ámbito en el cual se acepta el concepto de muerte cerebral cuando se trata de un donante, pero muchas veces se desconoce este mismo concepto cuando se trata de evitar el encarnizamiento terapéutico.

En realidad, el gran desafío que se impone es la necesidad de una mayor sintonía entre sociedad, poder legislativo y poder judicial, que impida la apropiación demagógica de las problemáticas y la disonancia entre normas y prácticas.

También es urgente que el derecho asuma los desafíos globales de la bioética más allá de su dimensión biomédica, haciendo suyos conceptos básicos de una convivencia social armónica que se relacionan con el desarrollo vertiginoso de la tecnociencia. Entre estos conceptos cabe destacar los imperativos de prudencia, de responsabilidad, de bioseguridad y de biodiversidad global, por nombrar sólo algunos.

En el caso de las sociedades latinoamericanas, estos desafíos cobran particular relevancia, pues junto con el pluralismo cultural y valórico nos encontramos con un pluralismo jurídico, esto es, con ordenamientos jurídicos paralelos que coexisten con el estatal, negando a éste la exclusividad en la producción de las normas de derecho. Si analizamos las realidades jurídicas de la región -Brasil, México, Perú, por nombrar sólo algunos ejemplos- podemos constatar que diversos grupos humanos asumen sus propios sistemas normativos, muchos de los cuales se colocan al margen del ordenamiento estatal. Esta situación debe impulsar aún más a los legisladores y a los jueces latinoamericanos a defender el pluralismo cultural y valórico, especialmente en el ámbito de la bioética, donde los espacios de libertad se hacen particularmente necesarios. 